\title{
5 a articulos
}

\section{- Arquitectura modernista en Granada}

\author{
Liliana Campos Pallarés \\ Universidad de Granada
}

\section{RESUMEN}

El Modernismo arquitectónico no tuvo un desarrollo espectacular en Granada, aunque la crítica histórico-artística ha tendido a infravalorar un patrimonio que, teniendo como principal escenario la Gran Vía, se extiende también a otras zonas de la ciudad. A través de un recorrido por la geografía urbana granadina, este trabajo analiza las huellas que el Art Nouveau dejó en sus fachadas, incluyéndose también en el estudio algunos monumentos funerarios del Cementerio de San José.

PALABRAS CLAVE: Arquitectura/ Modernismo/ Art Nouveau/ Granada.

\section{Art Nouveau arquitecture in Granada}

ABSTRACT

Arquitectural Art Nouveau has had no spectacular development in Granada, although artistic-historical criticism has tended to underestimate a heritage whose setting is the Gran Via, but which also extends to other parts of the city. Via a journey through the urban geography of Granada, this work analyses the marks left by the Art Nouveau on its façades, including some of the funeral monuments of the San José cemetery.

KEY WORDS: Architecture/ Modernism/ Art Nouveau/ Granada.

\section{Estado de la cuestión.}

El interés por el Modernismo en España se ha visto renovado en las últimas décadas, especialmente a partir de la de los 60, cuando se inicia una lenta revalorización de las manifestaciones artísticas adscritas a este estilo. Esta nueva estimación se ha traducido en un incremento del número de monografías y trabajos de investigación dedicados al mismo, que han permitido un estudio más amplio de su influencia, abarcándose lugares de la geografía española que hasta ese momento habían permanecido prácticamente ignorados, eclipsados por la importancia de Cataluña. Posturas como la de Oriol Bohigas, que hablaba de un Modernismo exclusivamente catalán ${ }^{1}$, han sido plenamente superadas, siendo cada vez más los Historiadores del Arte que centran su labor investigadora en el análisis de la influencia del Art Nouveau en otros muchos puntos del territorio nacional.

No obstante, y pese a que este nuevo impulso se ha afectado a todo el país, el foco andaluz -y especialmente Andalucía Oriental- carece todavía de estudios

* CAMPOS PALLARÉS, Liliana: "Arquitectura modernista en Granada", en Boletín de Arte n 32-33, Departamento de Historia del Arte, Universidad de Málaga, 2011-2012, págs. 69-90. Fecha de recepción: Noviembre de 2009.

1 BOHIGAS I GUARDIOLA, Oriol: Arquitectura modernista. Barcelona, Lumen, 1968. En un trabajo posterior, no obstante, el arquitecto catalán ampliaba, en cierto modo, esa visión restrictiva. Vid. BOHIGAS I GUARDIOLA, Oriol (1971): Reseña y catálogo de la arquitectura modernista. Barcelona, Lumen, 1983. 
monográficos que le otorguen la importancia que se merece. Los primeros escritos que hablan de un Modernismo español fuera de Cataluña lo hacen de forma tímida y subyugándolo siempre al referente catalán; en ellos, apenas si se hace mención a los casos andaluces ${ }^{2}$. La profesora Mireia Freixa admite que «la historiografía sobre el modernismo andaluz se ha centrado muy particularmente en la Andalucía Occidental, y sólo contamos con algún estudio muy puntual respecto a Málaga, Almería y

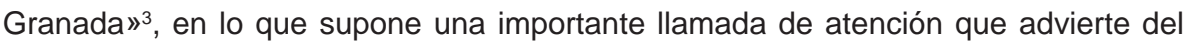
escaso interés que el Modernismo ha suscitado en dichas provincias. El investigador Pedro Navascués Palacios, por su parte, afirma, al referirse a tierras meridionales, que «el modernismo viene a cerrar un siglo de poca vitalidad arquitectónica en Andalucía ${ }^{4}$, para centrarse luego, casi de forma exclusiva, en el análisis de la arquitectura modernista perteneciente a la ciudad de Sevilla.

Los trabajos sobre Modernismo a nivel andaluz son escasos, y en la mayoría de los casos sólo forman una pequeña parte de obras o enciclopedias de temática mucho más amplia. Dos de los principales investigadores del Art Nouveau en Andalucía, Alberto Villar Movellán y Víctor Pérez Escolano, publican lo que supone el primer artículo que aborda la situación de la arquitectura modernista en el sur de la península5. El texto no está no exento de nociones generales básicas sobre el estilo y la situación económica y cultural de las provincias andaluzas a principios de la pasada centuria, que facilitan una rápida comprensión por parte del lector poco formado en temas artísticos; además, resultan muy interesantes los catálogos de edificios modernistas, que se incluyen junto con su localización en un plano, a pesar de que se realizan sólo para algunas localidades de Andalucía Occidental. Hemos de lamentar, sin embargo, el que la referencia a Andalucía Oriental consista en un breve párrafo en el que se engloban las ciudades de Granada, Málaga y Almería.

Años más tarde, Villar Movellán realiza un recorrido por los inmuebles que constituyen los más claros ejemplos de la vida del Modernismo en nuestra Comunidad6. De nuevo se resalta Sevilla como el centro que ofrece mayor atractivo, realizándose un análisis más profundo de las provincias occidentales que de aquellas orientales, a las que sólo se menciona en la parte final de la publicación. En el pequeño párrafo que dedica a Granada, destaca la importancia de la Gran Vía, que califica como «el muestrario más completo del Art Nouveau en Andalucía» ${ }^{7}$, citando a continuación algunos de los

2 El ejemplo más extremo lo encontramos en el brevísimo apartado que Juan Antonio Gaya Nuño dedica a la arquitectura modernista española al margen de la catalana, en el que ni siquiera hace referencia a la región andaluza. Este sucinto capítulo es, más un análisis serio de la situación, una mera enumeración de ciudades y arquitectos ibéricos que pueden adscribirse a este estilo. Vid. GAYA NUÑO, Juan Antonio: Arte del siglo XX, en AA.VV.: Col. Ars Hispaniae, v. 22. Madrid, Plus Ultra, 1977, págs. 41-42.

3 FREIXA SERRA, Mireia: El modernismo en España. Madrid, Cátedra, 1986, pág. 253.

4 NAVASCUÉS PALACIOS, Pedro: Arquitectura española: 1808-1914, en AA.VV.: Col. Summa Artis, v. 35 Madrid, Espasa Calpe, 1993, pág. 586.

5 PÉREZ ESCOLANO, Víctor y VILLAR MOVELLÁN, Alberto: "Arquitectura modernista andaluza", La Ilustración Regional, nº 4, Sevilla, 1974, págs. 57-58.

6 VILLAR MOVELLÁN, Alberto: "Modernismo en Andalucía”, en AA.VV.: Gran Enciclopedia de Andalucía, v. 10. Sevilla, Promociones culturales andaluzas, 1979, págs. 120-123.

7 Ibídem, pág. 122. 
arquitectos más sobresalientes que trabajaron en la ciudad en los inicios de siglo XX.

Del mismo autor es «El modernismo arquitectónico andaluz y su singularidad» ${ }^{8}$, un texto en el que ya encontramos un apartado propio para Andalucía Oriental, donde vuelve a hablar de la Gran Vía granadina como el aporte más interesante del Modernismo arquitectónico andaluz, y señala además en ella una manifiesta influencia de la escuela catalana. En las conclusiones de la ponencia, Villar diferencia dos áreas dentro de la estética modernista andaluza: por un lado, la Baja Andalucía, que recibe influencias de corte europeo; por el otro, Andalucía Oriental, de un mayor influjo catalán. Esta distinción supone, al fin, un importante reconocimiento de la solidez y personalidad que el Art Nouveau adquirió en territorio andaluz.

En una de las enciclopedias dedicada a nuestra región, que lleva por título Historia del Arte en Andalucía, Antonio de la Banda y Vargas hace una breve alusión a su modernismo arquitectónico, esta vez con mucha menos fortuna para Granada, a la que apenas si dedica unas líneas meramente alusivas ${ }^{9}$. No obstante, cita una casa de la localidad de Huéscar que constituye un buen ejemplo de la expansión de la arquitectura modernista por la provincia granadina, añadiendo una foto en la que se aprecia la hermosa fachada del inmueble.

Una de las obras más recientes sobre Arte en Andalucía es la escrita por los profesores Rafael López Guzmán e Ignacio Henares Cuéllar: Andalucía: cultura y diversidad; en ella, los autores destacan la presencia del Modernismo en las grandes vías que la incipiente burguesía andaluza de principios del siglo XX abre en la trama urbana de las capitales de la región, señalando en caso granadino como el mejor ejemplo ${ }^{10}$. Conscientes de la trascendencia artística de estos inmuebles, lamentan las destrucciones y sustituciones del patrimonio modernista que se produjeron en los años setenta del pasado siglo, y que suponen el mejor ejemplo de las nefastas consecuencias que la falta de respeto hacia nuestro legado histórico tuvo en las transformaciones urbanas del momento.

Para encontrar trabajos que profundicen más en el Modernismo propiamente granadino, habremos de acudir a revistas como Cuadernos de Arte de la Universidad de Granada o a guías de la ciudad. Sin embargo, estas referencias se integran, en la mayoría de los casos, dentro de textos de temática urbanística o referidos a determinadas zonas de la capital, y rara vez se articulan en base a la propia corriente artística. A ellas volveremos más adelante.

Antes de analizar el lugar que el Art Nouveau ocupa en estas publicaciones, hemos de referirnos a la revista La Alhambra, una de las primeras de carácter local que trata temas relacionados con las Bellas Artes. En sus 26 años de vida -de 1898 a 1924-, se publican en ella un par de artículos que versan sobre el Modernismo, aunque lo hacen desde una perspectiva no histórica y un tanto incierta, pues pertenecen a los

8 VILLAR MOVELLÁN, Alberto: "El modernismo arquitectónico andaluz y su singularidad", en AA:VV.: Actas del Congreso Internacional sobre el Modernismo español e Hispanoamericano. Córdoba, Diputación, 1987, págs. 169-189.

9 BANDA Y VARGAS, Antonio de la: "De la llustración a nuestros días", en AA.VV.: Historia del Arte en Andalucía, v. 8. Sevilla, Gever, 1991, págs. 247-259.

10 LÓPEZ GUZMÁN, Rafael y HENARES CUÉLLAR, Ignacio: Andalucía: cultura y diversidad. Madrid, Lunwerg, 2004, pág. 293. 
años de pleno auge del movimiento artístico. El primero de ellos, escrito por Luis Sáinz de los Terreros, constituye una dura crítica a la arquitectura del momento, tanto a la de corte historicista -mera «copia de formas antiguas» ${ }^{11}$ - como a la modernista -«conjunto de formas sin sentido [...] sin valor artístico alguno» ${ }^{12}$-. Según el autor, la arquitectura que le es contemporánea no cumple con su principal función, esto es, satisfacer las necesidades de su época y distinguirse, precisamente por ello, de las pasadas; De los Terreros no sólo no considera las formas modernistas como algo novedoso, sino que, además, las priva de cualquier tipo de valor estético.

El segundo artículo resulta ser un fragmento del libro Las Catedrales de España, de Ricardo Benavent ${ }^{13}$. La opinión que el Modernismo merece para dicho autor es absolutamente negativa, llegando éste a afirmar que es «el periodo más decadente que el arte, en sus cinco manifestaciones, ha tenido» ${ }^{14}$; utiliza, para describir el Art Nouveau, adjetivos como "violento", "fuera de proporciones", "deforme" o "vicioso", culpando a los catalanes de que tan grotesco estilo haya penetrado en tierras españolas. La visión de Benavent ni siquiera aboga por un estilo arquitectónico nuevo y modernizante, sino que alude a la grandeza de construcciones de grandes civilizaciones pasadas, como la persa o la egipcia, de las que cree que sería interesante una reconstrucción, al igual que se ha hecho con templos y edificios civiles griegos o romanos ${ }^{15}$.

Ocupándonos ya de publicaciones más recientes, y más concretamente de la citada Cuadernos de Arte de la Universidad de Granada, es necesario advertir acerca de las marcadas diferencias entre las posturas de los distintos estudiosos del Modernismo que escriben en la revista: mientras que Antonio Checa Godoy afirma que «el Modernismo pasa de puntillas por Granada y apenas algunas modestas viviendas de dos o tres plantas dispersas por la ciudad muestran su influencia» ${ }^{16}$; para José Álvarez Lopera, cuyo artículo se publica en la misma revista tan sólo un año después, la demolición de algunos edificios de la Gran Vía supone «la desaparición del ambiente modernista de la calle, muy marcado y de una homogeneidad que le prestaba un cierto carácter, en absoluto despreciable» ${ }^{17}$. Otros investigadores, como Ángel Isac Martínez de Carvajal, consideran que el Modernismo local se ve entremezclado en las fachadas de los inmuebles con otros elementos pertenecientes a un eclecticismo historicista o a modelos regionalistas ${ }^{18}$.

11 SÁINZ DE LOS TERREROS, Luis: "El estilo moderno en arquitectura en España", La Alhambra, n²21, Granada, 1907, pág. 230.

12 Ibídem, p. 230.

13 BENAVENT I FELIU, Ricardo: "Poder expresivo de la Arquitectura", La Alhambra, nº 376, Granada, 1913, págs. 501-504.

14 Ibídem, pág.503. Las cinco manifestaciones del arte a las que se refiere son: literatura, pintura, escultura, música y arquitectura.

15 Ibíd., pág.503.

16 CHECA GODOY, Antonio: "Sociedad y urbanismo en la Granada contemporánea (1808-1974)", Cuadernos de Arte de la Universidad de Granada, nº 11, 1973-1974, pág. 349.

17 ÁLVAREZ LOPERA, José: "Granada y su destrucción en el año europeo del patrimonio arquitectónico", Cuadernos de Arte de la Universidad de Granada, nº 12, 1975, pág. 175. De la opinión del historiador granadino participa el profesor José Manuel Gómez-Moreno Calera, como manifestará en su artículo "Reflexiones sobre el deterioro monumental de Granada", que se incluye dentro del número 20 de la publicación, del año 1989. 18 ISAC MARTÍNEZ DE CARVAJAL, Ángel: "Transformación urbana y renovación arquitectónica de Granada. Del "plano geométrico" (1846) al Gran Parque (1929)", Cuadernos de Arte de la Universidad de Granada, $\mathrm{n}^{\circ}$ 18, 1987, págs. 207-230. 
Respecto a las guías de Granada, son de obligada mención las que, entre finales del siglo XIX y principios del XX, realizaran los eruditos locales Manuel Gómez Moreno, Francisco de Paula Valladar y Antonio Gallego Burín: la Guía de Gómez Moreno resultó ser la más completa de las que se publicaron entonces ${ }^{19}$; la escrita por Valladar es de una escritura clara y fluida, a pesar de su manifiesta pereza a la hora de describir los edificios ${ }^{20}$; mientras que la de Gallego y Burín fue reeditada más de una decena de veces a lo largo del pasado siglo, y supone una importantísima fuente de conocimiento para el estudio de los inmuebles que han ido desapareciendo en la ciudad hasta nuestros días, a pesar de que la fiebre destructiva ya había invadido Granada décadas antes de que se publicara ${ }^{21}$. Las dos primeras -sobre todo la de Gómez Moreno- son demasiado tempranas como para incluir dentro de sus páginas la arquitectura modernista, y la de Gallego y Burín no realiza ninguna alusión a ella, quizás debido al poco interés que dicho estilo suscitaba en aquellos años.

Nuevos paseos por Granada y sus contornos es una interesante obra en varios volúmenes que recoge textos literarios, históricos y artísticos acerca de la ciudad, y en la que Juan Gay Armenteros exalta la decoración modernista de la Gran Vía, que califica de «imaginativa, desbordada en algunos casos, caprichosa y sin sentido en otros, pero nunca anodina» ${ }^{22}$.

Las posteriores guías de la ciudad, que generalmente analizan de forma individual sus edificios más emblemáticos, están lejos de recoger todos los inmuebles de interés modernista que en ella se dan. La Guía de arquitectura de Granada de Carlos Jerez Mir, apenas si señala un ligero carácter modernista en muy contadas construcciones $-\mathrm{y}$, curiosamente, ninguna perteneciente a la Gran Vía-, como el número 7 del Paseo de la Bomba o la conocida como Villa Pineda, en la Antigua Carretera de Málaga ${ }^{23}$. Otro de estos manuales, con idéntico título a la anterior, es el elaborado por Eduardo Martín Martín y Nicolás Torices Abarca; en él, el único edificio modernista al que se hace referencia es el interior de la joyería La Purísima de la calle Reyes Católicos, que ha sido recientemente demolido, dejándose en pie tan sólo la fachada ${ }^{24}$. En la Guía de la Granada desaparecida, Juan Manuel Barrios Rozúa realiza un análisis de los edificios destruidos durante los siglos XIX y XX sin hacer mención alguna a los edificios modernistas de la ciudad que ya no se encuentran en pie, pese a tratarse de una publicación relativamente reciente ${ }^{25}$.

Granada en siete paseos es un breve y ameno recorrido por la historia, cultura y

19 GÓMEZ MORENO, Manuel: Guía de Granada. Granada, Ventura, 1892.

20 VALLADAR Y SERRANO, Francisco de Paula (1890): Guía de Granada. Historia, descripciones, artes, costumbres e investigaciones arqueológicas. Granada, Universidad, 2000.

21 GALLEGO Y BURÍN, Antonio (1961): Granada: guía artística e histórica de la ciudad. Granada, Comares, 1996.

22 GAY ARMENTEROS, Juan: “Un paseo por el centro de Granada”, en AA.VV.: Nuevos paseos por Granada y sus contornos, v. 1. Granada, Caja General de Ahorros, 1992, pág. 442.

23 JEREZ MIR, Carlos: Guía de arquitectura de Granada. Sevilla, Junta de Andalucía, Consejería de Cultura, 1996, págs. 273 y 280.

24 MARTÍN MARTÍN, Eduardo y TORICES ABARCA, Nicolás: Granada: guía de arquitectura. Sevilla: Dirección General de Arquitectura y Vivienda, 1998, p. 260.

25 BARRIOS ROZÚA, Juan Manuel: Guía de la Granada desaparecida. Granada, Comares, 1999. 
arte granadinos, más apto para quien se acerca por primera vez a la ciudad que para el estudioso que quiera profundizar en el tema ${ }^{26}$. A través de siete itinerarios distintos, $\mathrm{M}^{\mathrm{a}}$ Carmen Alonso Morales describe las principales áreas urbanas que las distintas etapas históricas han ido conformando, siendo la última de estas rutas la que atraviesa la zona más reciente del casco histórico, que abarca la Gran Vía, Puerta Real y la Carrera de la Virgen. A propósito de la primera, la autora sostiene que «ahora podría ser un excelente ejemplo de avenida modernista, con las fachadas de cada edificio con sus características particulares, pero durante los años sesenta y setenta del siglo XX, muchas de las casas originales fueron derribadas y ocupadas por edificios horribles, cuya construcción sólo debió de estar determinada por la enorme especulación inmobiliaria del momento»» ${ }^{27}$.

La última de estas guías es la publicada en 2006 con el título Guía turística de Granada y su provincia, escrita en su mayor parte por profesores del departamento de Historia del Arte de la Universidad de Granada ${ }^{28}$. Está compuesta por dos volúmenes, el primero de los cuales se centra principalmente en el análisis de la arquitectura de los distintos barrios de la capital, citando en algunos casos también ejemplos de pinturas y esculturas ligadas a determinados inmuebles. Curiosamente, no se dedica más de media página al estudio de la Gran Vía, a la que se atribuye un repertorio de formas historicistas, eclécticas y "pseudomodernistas". El segundo tomo está dedicado a la provincia de Granada, y en él hemos de destacar la mención que se hace de la casa modernista de Huéscar, señalándose sus claras reminiscencias catalanas y estableciéndose como un excepcional ejemplo de vanguardia arquitectónica dentro de la urbe ${ }^{29}$.

La Gran Vía de Colón ha sido, sin duda, la arteria granadina que más trabajos de investigación ha generado en las últimas décadas en la ciudad, además de ser su principal escenario modernista, pues su construcción coincidió con los años de apogeo de este estilo. No obstante, monografías dedicadas a dicha calle como las de Manuel Martín Rodríguez o Gabriel Pozo Felguera ${ }^{30}$, se centran más en los aspectos económicos y culturales que envolvieron la erección de los inmuebles que en la estética de sus fachadas.

El documento más completo que hasta la fecha poseemos acerca del Modernismo granadino es el que Emilio Ángel Villanueva Muñoz publica dentro del libro que recoge las ponencias y comunicaciones presentadas en el Congreso Nacional de Arquitectura Modernista, celebrado en Melilla en abril de $1997^{31}$. Se trata de un estudio del Modernismo almeriense y granadino, dedicando especial atención, en el último caso, a la Gran Vía de Colón, sin menospreciar otros edificios con homólogas decoraciones dispersos por el casco antiguo y la periferia. La diferencia entre éste y otros escritos que hablan sobre la Gran Vía es que, en este caso, es el Modernismo el

26 ALONSO MORALES, Ma Carmen: Granada en siete paseos. Granada, Centro de Lenguas Modernas, 2000.

27 Ibídem, pág. 172.

28 AA.VV.: Guía turística de Granada y su provincia. Granada, Fundación José Manuel Lara, 2006.

29 Ibídem, v. 2, pág. 92.

30 MARTíN RODRÍGUEZ, Manuel: La Gran Vía de Granada. Granada, Caja General de Ahorros, 1986; POZO FELGUERA, Gabriel: La Gran Vía de Granada: un siglo. Granada, Caja Rural, 1997.

31 VILLANUEVA MUÑOZ, Emilio: "Ciudad y arquitectura modernista en la Andalucía Oriental", en AA.VV.: Arquitectura y Modernismo: del historicismo a la modernidad. Granada, Universidad, 2000, págs. 221-246. 
argumento principal, estructurador del texto ${ }^{32}$.

Para finalizar este barrido historiográfico, hemos de citar una guía de Granada que, hace tan sólo tres años, sacó a la luz el periódico local Ideal, que lleva por título Granada en tus manos. En el quinto tomo, dedicado al centro histórico de la ciudad, el profesor Ricardo Anguita Cantero realiza un minucioso estudio acerca de la construcción de la Gran Vía, analizando, uno a uno, los principales edificios que, a lo largo del siglo XX, se han levantado en ella. La postura del investigador es muy crítica con respecto a las voces que exaltan dicha calle como un claro ejemplo de conjunto modernista homogéneo, y califica de "semimodernistas" algunas de las características formales que se han venido englobando dentro de la estética del Art Nouveau ${ }^{33}$.

Los datos facilitados a lo largo de estas líneas ponen de manifiesto la falta de atención por parte de los estudiosos de la arquitectura hacia el Modernismo en Granada, que contrasta con el interés que ejemplos de otros movimientos artísticos, más fructíferos en cuanto a número de construcciones, han despertado en los historiadores del arte. Concluimos este apartado afirmando que, pese a las advertencias que décadas atrás realizaron investigadores como Mireia Freixa o Alberto Villar acerca del estadio embrionario en el que se encuentra la investigación referente al Modernismo en Andalucía Oriental, la situación no ha mejorado, y exige una revisión urgente que permita una análisis más profundo del que hasta ahora se ha realizado. Quizás así se tenga una idea menos fragmentaria de la influencia real que dicho estilo ejerció en estas tierras meridionales.

\section{El MODERNISMO EN LOS DISTINTOS BARRIOS GRANADINOS.}

A continuación, y con la intención de aproximarnos a la situación real del movimiento artístico en Granada, pasamos a un análisis pormenorizado de la arquitectura de influencia modernista de la ciudad a través de las distintas áreas que componen el centro urbano.

\subsection{BarRio de LA VIRgen}

La zona que circunda la Basílica de Nuestra Señora de las Angustias es el escenario de algunos de los ejemplos más interesantes de la ciudad, que, a diferencia de los de la Gran Vía, suelen ser olvidados en las obras que tratan el Modernismo granadino.

El primero de ellos es el inmueble situado en la calle Ancha de la Virgen número

32 Villanueva concluye, no obstante, con una visión realista de la fortuna del Modernismo en Andalucía, afirmando que éste no fue capaz de eclipsar al Eclecticismo, cuya estética inundó gran parte de las construcciones de la época.

33 ANGUITA CANTERO, Ricardo: "La Gran Vía de Colón: la construcción de una calle moderna en el centro histórico de Granada", en AA.VV.: Granada en tus manos, v. 5. Granada, Corporación de Medios de Andalucía, 2006, págs. 16-56. 


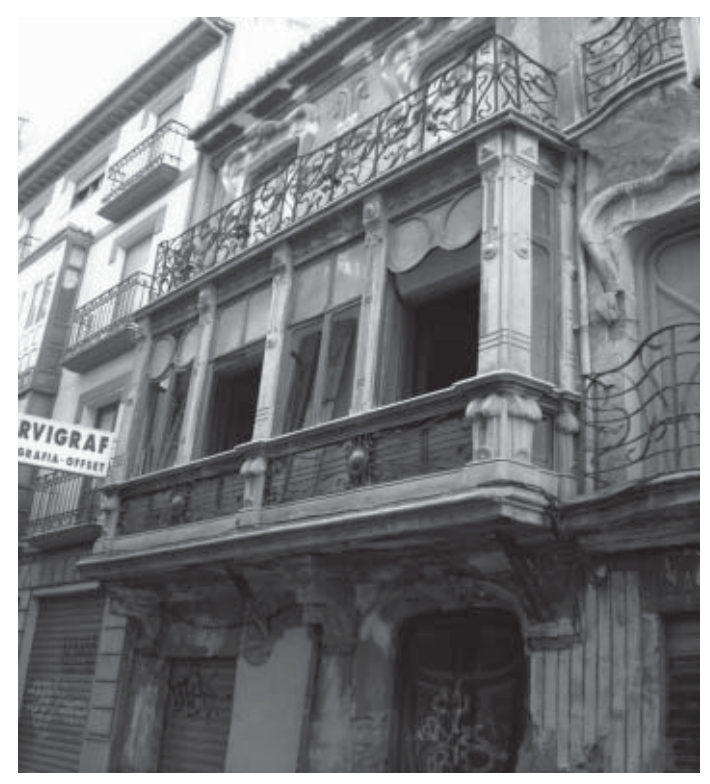

1. Detalle de la fachada de Ancha de la Virgen 5.

5, transversal a la Carrera del Genil ${ }^{34}$ [1]. Está compuesto de planta baja, y dos pisos superiores de tres vanos cada uno: el central está constituido por un cierre corrido, que ocupa los huecos izquierdo y medianero, y una ventana en la parte derecha; en el tercer y último nivel, los dos vanos que coinciden con el cierre inferior comparten un mismo balcón. Destacan las molduras superiores de las ventanas, de una blandura volumétrica que contrasta con el esquematismo ornamental del cierre, de motivos que enlazan con la vertiente modernista geométrica. También la rejería del conjunto combina formas organicistas -el latiguillo- con otras más propias de la Sezession -los círculos concéntricos y las tres bandas paralelas-. El muro está decorado con un esgrafiado de motivos vegetales de corte clasicista; la puerta principal, de arco carpanel apainelado, nos ofrece un magnífico trabajo en carpintería, con una interesante talla de elementos florales que se entrecruzan, y que también lucen el característico latiguillo. Lamentablemente, el bloque se encuentra en un pésimo estado de conservación, consecuencia de una situación de abandono sufrida durante muchos años, que ha desvirtuado en gran medida su belleza y originalidad.

En esa misma calle, y haciendo esquina con Enriqueta Lozano, se ubica el inmueble número 25. Consta de semisótano, formado por sillares planos y rústicos, una planta inferior, dos pisos sobre ella separados por líneas de impostas, y un tercero, con una amplia terraza, añadido con posterioridad. De nuevo encontramos el

34 Uno de los pocos investigadores que ha recordado la importancia de este bloque, aunque sin detenerse en su análisis artístico, ha sido Emilio Villanueva Muñoz. Vid. VILLANUEVA MUÑOZ, Emilio: op. cit., pág. 245, nota 15. 
esgrafiado cubriendo buena parte del exterior de las dos plantas superiores, aunque en este caso se trata de un motivo floral estilizado muy cercano a la vertiente geométrica del Modernismo, que le aporta un carácter único dentro de la arquitectura de la ciudad. En el mirador del lado menor de la fachada, hecho en madera, se aprecian las tres líneas paralelas propias de esta variante, que también aparecen en las cartelas o pinjantes que hay entre los huecos del segundo piso del mismo muro. La puerta de entrada está adornada con flores de largos y angulosos tallos, que siguen la línea del esquematismo que predomina en el edificio. Junto a esta estilización ornamental aparecen, asimismo, otros elementos que tienden a un mayor naturalismo, entre los que destacan las carnosas hojas situadas en los vértices superiores del recercado de los vanos, todos ellos adintelados.

En una de las calles paralelas a Ancha de la Virgen, que recibe el nombre de Mirasol, se sitúa el edificio número 24, sencillo y de una sobria fachada en la que, sin embargo, llaman la atención las molduras de sobreventana del primer piso, de un cierto interés modernista. Se trata de un tipo de moldura curva, en la que sobresale ligeramente la clave, decorada con una gran flor en el centro y largas ramas que se extienden a los lados. Será éste un esquema que se repetirá, tanto de forma idéntica como con pequeñas variaciones, en numerosos edificios del casco antiguo de la ciudad.

Ya en la Carrera del Genil, y justo a la izquierda de la iglesia de Nuestra Señora de las Angustias, se ubica el Bar Granados, que ocupa la planta baja de un bloque con tres pisos superiores, y cuyos frentes están prácticamente desornamentados. Las puertas de madera de dicho bar contrastan, no obstante, con el resto del edificio, pues poseen un carácter modernista conferido por el trazado curvilíneo de los cuarterones superiores y de los travesaños que dividen las tres hojas de abajo.

El Paseo de la Bomba es, sin duda, uno de los mejores escenarios de arquitectura burguesa de principios del siglo XX de la ciudad. Surgió de la urbanización de la antigua Huerta de la Estefanía hacia el año 1905, y se levantaron en él hermosos chalets rodeados de jardines que aportan a la calle un aspecto muy señorial. El primero de ellos es el número 6, que corresponde a las tendencias regionalistas de moda en la época, aunque con un estilo que enraíza más bien con la arquitectura tradicional del norte, lo que le aporta un carácter particular. Es de resaltar el uso generoso que se hace de la madera, que se extiende a balcones, aleros y miradores. Nuestro interés se centra en los huecos del primer piso de la fachada que da al Paseo, pues sobre las contraventanas presentan una sinuosa decoración vegetal de marcada esencia modernista ${ }^{35}$.

El siguiente edifico de interés de la calle es el número 7, en el que apreciamos un mayor número de detalles de raíz modernista, insertos dentro del gusto historicista que impera en la ornamentación. Un ejemplo de ello es el gran cierre de su fachada, cuyas columnas de "pata de elefante" -característica típica del Art Nouveau- aportan

35 Desgraciadamente, una de esas placas ha sido perforada para colocar sobre ella un aparato de aire acondicionado. 

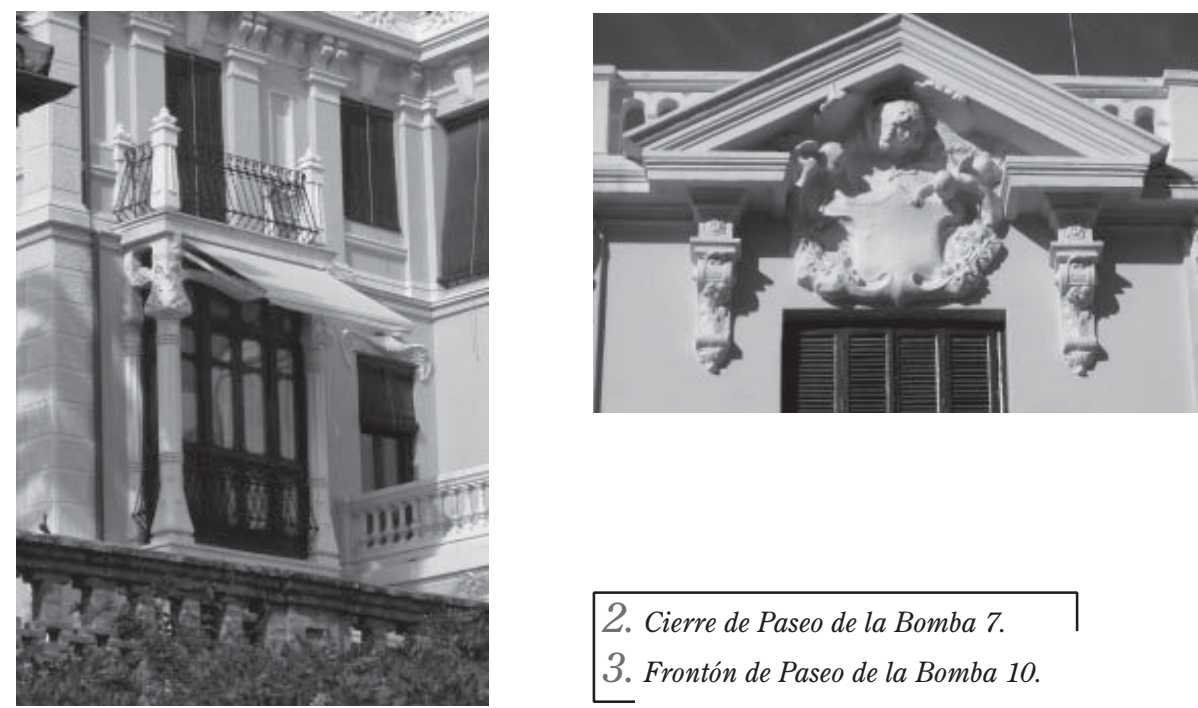

2. Cierre de Paseo de la Bomba 7.

3. Frontón de Paseo de la Bomba 10.

organicidad al conjunto [2]. Son igualmente destacables las molduras de los vanos del primer piso, aladas y con adornos vegetales en relieve, así como los elementos florales que se repiten de forma seriada a lo largo de la cornisa.

Por último, hemos de hacer alusión el chalet número 10 del Paseo, actual Centro Juvenil Nazaret. Su fachada es sobria, pero de gran elegancia, con una escalinata curva de acceso que rodea la torreta circular adosada al lateral izquierdo y que discurre sobre parte del semisótano. Su decoración, aunque escasa, es muy significativa: en el frontón triangular desventrado del extremo derecho, que está ligeramente adelantado con respecto al cuerpo central, se dan relieves de muy blandas formas, que se ajustan a la cúspide del mismo y enlazan con el cuerpo inferior aprovechando su abertura [3]. Adosados a los flancos se disponen dos pinjantes en los que se puede apreciar la fecha de construcción del edificio -1910- en caracteres completamente modernistas, y que se repiten en la parte trasera del edificio, donde la terraza que remata la fachada se sustituye por un tercer piso. Bajo la balaustrada de dicha terraza, cartelas de decoración vegetal se alternan con molduras escultóricas antropomorfas, de igual plasticidad que los anteriores relieves; mientras que los antepechos de los huecos del segundo piso de la fachada se decoran con una cruz en aspa que evoca el Modernismo de la Sezession. 
4. Moldura de Rejas de la Virgen 4.

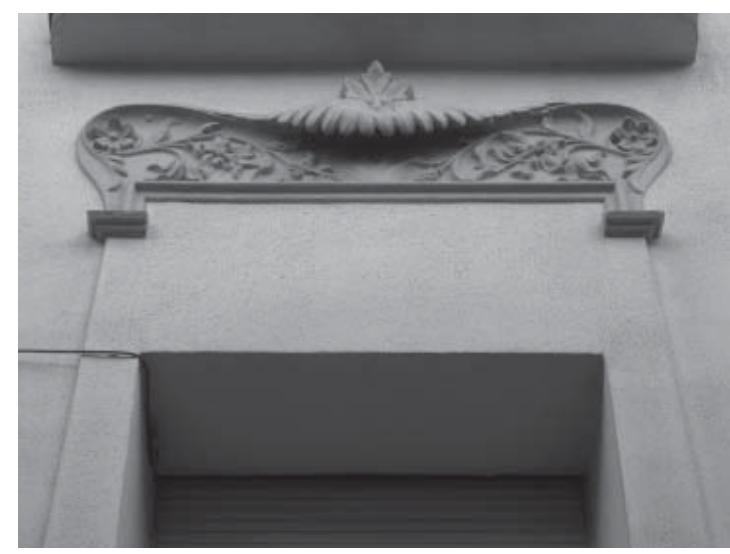

\subsection{Barrio de Fígares y San Antón.}

Este barrio es fruto de los programas de construcciones económicas llevados a cabo durante la dictadura de Primo de Rivera, por la necesidad de realojar a la población que había sido expulsada de la zona de San Matías-Manigua debido al incremento de las demoliciones; y surge de un proyecto del arquitecto Matías Fernández-Fígares, elaborado en $1925^{36}$. La calle San Antón, que conforma otro barrio adosado al anterior, actúa de límite con el centro neurálgico de la ciudad, Puerta Real.

La influencia del Modernismo en este sector urbano es mucho más modesta que en el caso anterior, y se manifiesta en elementos ornamentales muy localizados de determinadas construcciones, como festones florales con guirnaldas -como es el caso del número 10 de la calle Padre Alcover o el 8 de la calle Horno del Espartero-, o flores hexalobuladas de carácter geométrico de las que penden las tres bandas paralelas -como los esgrafiados que decoran los dinteles de los vanos del número 10 del Horno del Espartero-.

Un ejemplo a destacar de esta zona es el de la calle Rejas de la Virgen número 4, cuyas molduras de sobreventana del primer piso son idénticas a las vistas en el chalet número 7 del Paseo de la Bomba [4]. En esa misma calle, el inmueble número 10 presenta una sencilla, aunque interesante, decoración sobre los dinteles de los cuatro huecos de su fachada, consistente en una carnosa flor de la que surgen ondulantes tallos, y que también aparece sobre la cornisa del citado chalet. Todo esto nos habla de diseños decorativos predeterminados que seguramente han sido elegidos por catálogo.

En la calle San Antón, el número 20 posee un gran mirador de fábrica abierto y curvo, ornamentado en los finos pilares que separan los vanos y los espacios

36 ISAC MARTÍNEZ DE CARVAJAL, Ángel: "La reforma burguesa de la ciudad desde sus inicios hasta Gallego y Burín (1850-1951)", en AA.VV.: Nuevos paseos por Granada y sus contornos, v. 1. Granada, Caja General de Ahorros, pág. 384. 


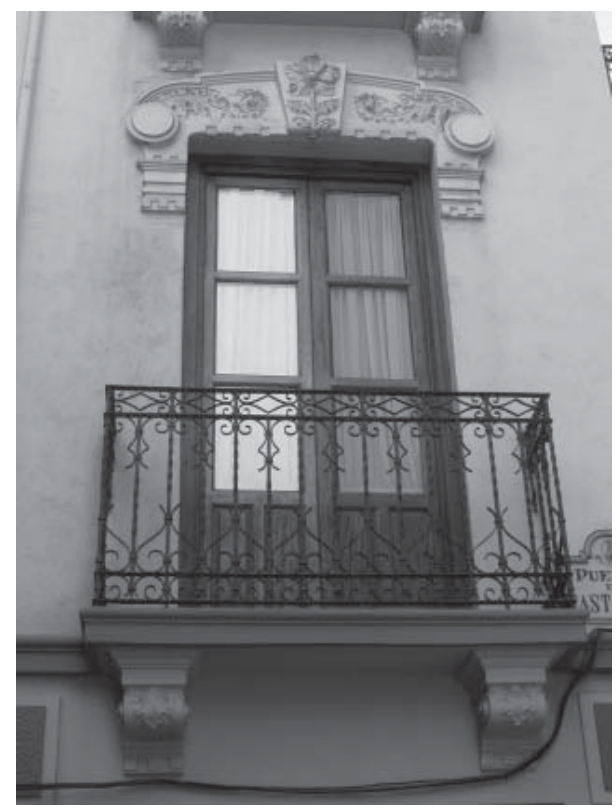

5. Balcón de San Antón 37.

entre cuerpo y cuerpo con motivos derivados del Modernismo geométrico.Asimismo, lasménsulas que sostienen el cierre, de gran vuelo, están decoradas en su parte central con flores de largos tallos de carácter muy esquemático.

Nos detenemos ahora en el número 37 de la misma vía, de nuevo a causa de las monteras de los vanos; en ellas apreciamos una mezcla de formas geométricas y naturalistas: poseen un perfil lineal, con círculos concéntricos en los laterales propios del sezessionismo vienés; la clave, que está resaltada, y el espacio interior de las monteras, se adornan con elementos vegetales derivados del Art Nouveau [5].

El número 44, situado en la parte más baja de la calle, forma, junto con el 46, las llamadas "Casas de López de Medina", proyectadas por el arquitecto Francisco Giménez Arévalo hacia el año $1900^{37}$. De él cabe señalar las ménsulas que sostienen los balcones del segundo piso, en las que hallamos una carnosa decoración floral. Los pretiles calados de la baranda de la cubierta aterrazada son muy similares a los que pocos años después se harán en edificios de la Gran Vía, como el número 9.

\subsection{Barrio de la Magdalena}

Se trata de una antigua y amplia barriada que discurre en paralelo a la calle Recogidas, $y$ que ha sufrido grandes transformaciones a lo largo de los siglos XIX y $X X$, tendentes a una mejora de las condiciones higiénicas y a un lavado de cara, en aras de adecuar su aspecto al gusto burgués de la época. En los bloques construidos durante el primer tercio del siglo pasado, puede apreciarse un cierto influjo modernista, más acusado en unos casos que en otros.

Quizás el ejemplo más destacado sea el número 5 de la calle Arco de las Cucharas, perpendicular a la Plaza de Bibarrambla. Estando sus muros exteriores

37 AA.VV.: Guía turística..., v. 1, pág. 89. 
6. Detalle de la fachada de Arco de las Cucharas 5.

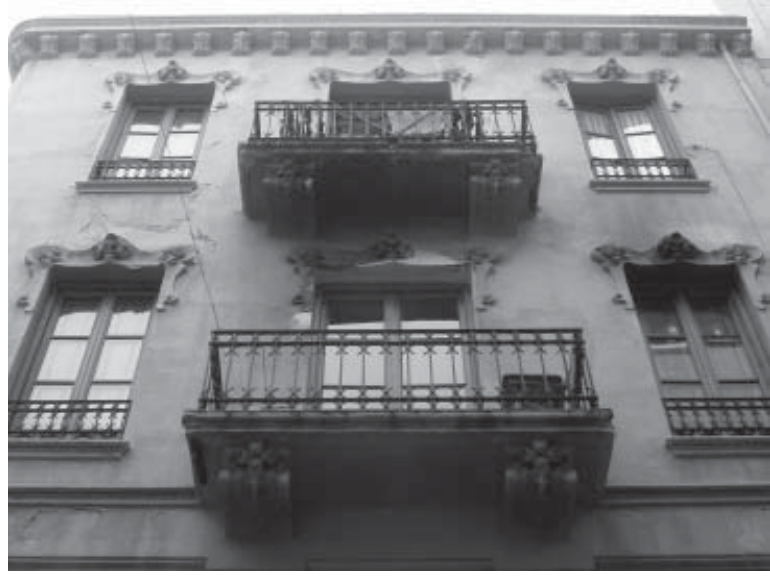

prácticamente exentos de decoración, hemos de subrayar, sin embargo, las bulbosas molduras de los dinteles sobre los vanos del tercer y cuarto piso, en las que nuevamente aparece decoración floral, de inequívoco carácter modernista [6].

En la misma Plaza de Bibarrambla, los inmuebles 12 y 15 presentan, dentro de un lenguaje general historicista, determinados elementos ornamentales de tipo vegetal de tendencias modernistas. En el caso del segundo edificio, se dan tanto motivos florales naturalistas -en los antepechos del cierre de la calle central y las molduras de los dinteles de la dos primera plantas-, como decoración de cierta rigidez geométrica -concentrada en las sobreventanas del tercer y último piso- que recuerdan a la escuela vienesa.

No muy lejos de allí, en el número 1 de la calle Boteros, paralela a la Plaza de Bibarrambla y perpendicular a Arco de las Cucharas, encontramos un bloque que hace esquina con la Placeta de Santo Cristo. Está compuesto por cuatro pisos que disminuyen en altura conforme se asciende, separados del ático superior por una cornisa, bajo la que se disponen festones florales de largos pinjantes que se corresponden con la filiación geométrica de las bandas paralelas y círculos concéntricos de los dinteles de los balcones del tercer piso.

En la calle Puentezuelas, una de las principales del barrio, el número 34 es un bellísimo inmueble de dos pisos sobre la planta baja y fachada de paramento fajeado. Destacan las molduras aladas sobre los huecos, cuyas formas curvas evocan el Modernismo más orgánico, y que se adornan con discos cerámicos de diversos colores característicos del estilo regionalista [7].

En algunos bloques del barrio se impone un tipo de ornamentación muy simple, que responde en su mayor parte al esquematismo del Modernismo geométrico. Podemos citar, en este sentido, los inmuebles 22 y 1 de las calles Jardines y Conde de las Infantas respectivamente, con los ya mencionados círculos concéntricos y bandas dispuestas en paralelo como protagonistas de sus fachadas. 


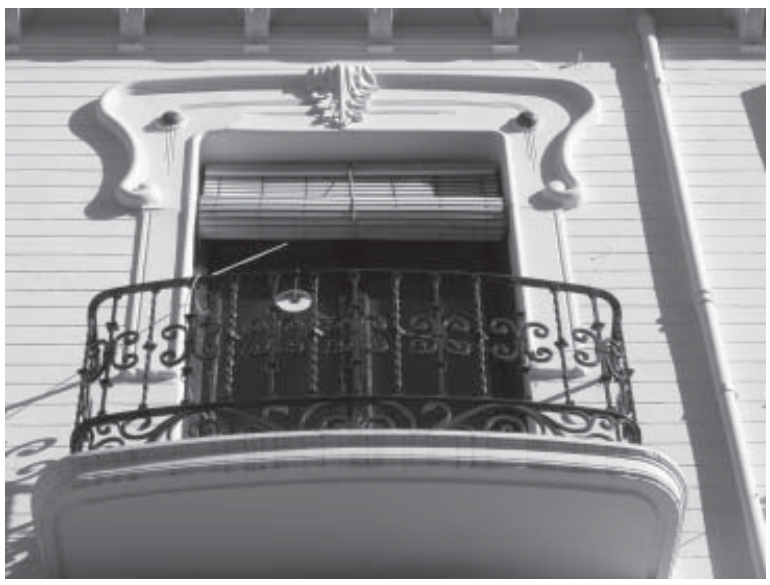

7. Vano de Puentezuelas 34.

Hemos de hablar nuevamente de esquemas decorativos que se repiten, especialmente en lo que a las molduras de los dinteles se refiere. El primer piso del inmueble número 21 de la calle Jardines, con tres vanos y un balcón corrido, posee monteras aladas con remates de formas vegetales que veremos en el número 19 de la Gran Vía; por su parte, las del número 31 de la calle Gracia, con relieves de flores y tallos, se dan también en el 7 de la calle Párraga, que pertenece a la misma barriada; finalmente, las molduras del primer cuerpo del bloque sin número del Callejón de Arjona, idénticas a las del edificio ya visto de la calle Mirasol, vuelven a aparecer en el número 1 de la Plaza Campo Verde, un ensanche de la calle Alhóndiga.

Otro aspecto interesante en lo que a este barrio se refiere es el de las ménsulas y modillones de las fachadas, que suponen un amplio muestrario de formas que van desde un Historicismo clasicista, con hojas de acanto y lanceoladas de carácter simétrico, hasta el naturalismo del Art Nouveau. A este último grupo pertenecen las ménsulas del número 3 de la calle Alhóndiga, de forma completamente cúbica, a la que se añaden una flor tetralobulada en la cara frontal, y enredados tallos con hojas en sus laterales y parte inferior. Son asimismo resaltables las de las construcciones, citadas con anterioridad, de las calles Arco de las Cucharas y Callejón de Arjona, que, junto con las del inmueble Buensuceso número 21, conforman un único modelo: se trata de pequeñas ménsulas con una flor de cuatro pétalos en el frontal, de cuyo tallo nacen otras dos flores gemelas de menor tamaño. 


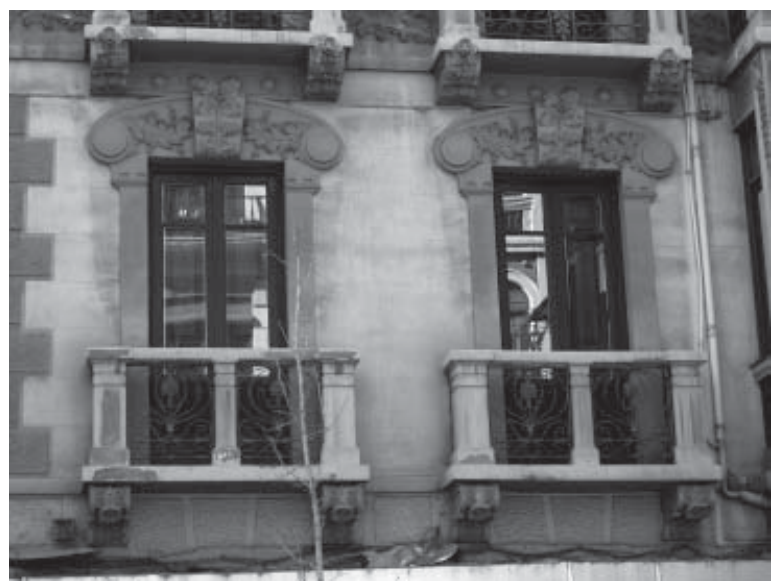

\subsection{Gran Vía y alRededores.}

La llamada "Gran Vía del azúcar", en alusión a su promoción por parte de una burguesía enriquecida por la actividad azucarera, es, sin lugar a duda, la calle que concentra el mayor número de fachadas de influencia modernistas de la ciudad, a pesar de que los derribos de bloques originales y su sustitución por edificios que nada tienen que ver con la línea estética de la vía, hayan falseado su primitiva imagen. Su apertura se llevó a cabo a costa del derribo de buena parte de las tortuosas y estrechas calles de la medina medieval, en una época -finales del s. XIX y principios del XXciertamente propicia para la proliferación del Art Nouveau en las nuevas fachadas. Sin embargo, y pese a todas las condiciones favorables para ello, el desarrollo del Modernismo no fue espectacular en la Gran Vía, si bien es cierto que no resulta en absoluto desdeñable.

Podría decirse que el lenguaje imperante dentro del conjunto es el Eclecticismo, lo que quizás demuestra una cierta falta de valentía por parte de la burguesía granadina a la hora de apostar por una estética rompedora, distinta a todo lo que hasta ese momento se había construido en la ciudad. Es cierto, por otra parte, que en buena parte de los edificios pertenecientes a las fases primitivas de construcción encontramos, en mayor o menor medida, y más o menos insertos en otras formas de corte más clasicista, elementos que manifiestan la influencia del Modernismo.

Curiosamente, los frentes arquitectónicos de la acera de los números impares concentran un número mucho mayor de componentes modernistas que la de los pares. Hablamos, en concreto, de las cuatro casas finales -números del 53 al 59-, que, como apunta Gabriel Pozo Felguera, «marcan un estilo muy modernista, muy influenciado por la obra de Gaudí, y alejado de lo que fue el eclecticismo francés que marcó la mayor 


Q: articulos Liliana Campos Pallarés

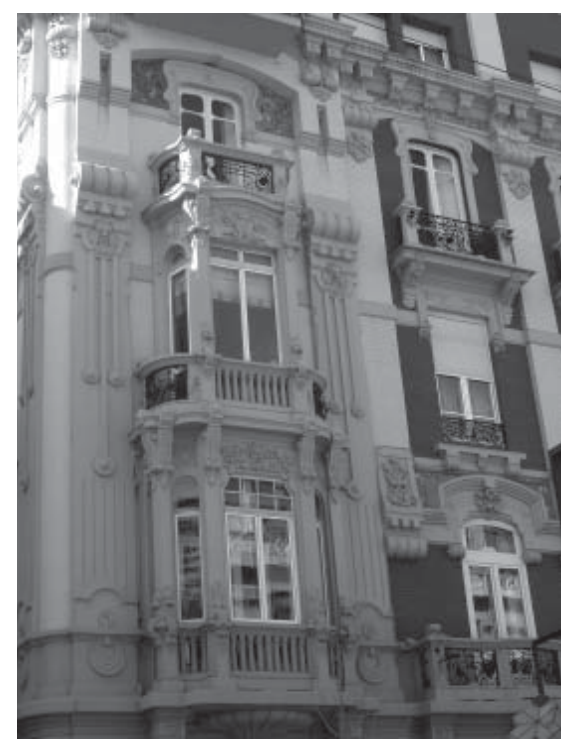

9. Detalle de la fachada de Gran Vía 29.

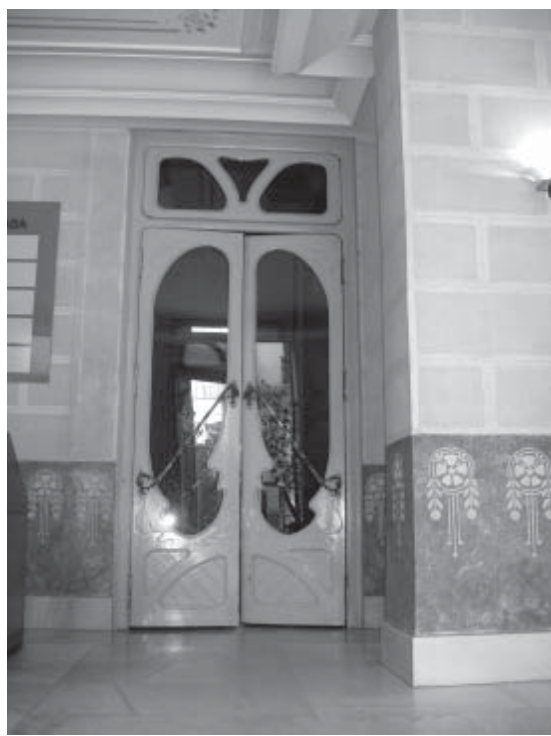

10. Puerta interior del Edificio Colón.

parte de construcciones de edificios de la Gran Vía»»38. Construidas entre 1908 y 1912 por iniciativa de Ricardo Castella González-Aurioles, miembro de una familia de banqueros, suponen -sobre todo en lo que respecta a los números 53 y 55- una interesante muestra de ornato modernista, con decoración floral en relieve que se extiende por cornisas, molduras de sobreventana, columnas y antepechos de miradores.

Uno de los cierres de fábrica más bellos de toda la calle es el del número 45, que, aunque inserto en una fachada de composición historicista, posee una rica ornamentación vegetal calada que enraíza fuertemente con la tradición Art Nouveau. El inmueble 41, por su parte, presenta decoración modernista que se traduce en las profusas formas florales, vegetales e incluso animales que invaden las molduras de sus dinteles, las barandillas de sus balcones y las ménsulas [8].

Siguiendo en la misma acera, el número 33 representa una excepción en la línea estética que sigue la mayor parte del Modernismo de la Gran Vía, pues enlaza con las corrientes geométricas representadas por la Sezession vienesa y la Escuela de Glasgow. No obstante, las ménsulas que sostienen tanto las balconadas como el mirador están decoradas con un lenguaje floral propio del Modernismo de corte naturalista.

El número $29 \mathrm{es,} \mathrm{posiblemente,} \mathrm{el} \mathrm{inmueble} \mathrm{donde} \mathrm{el} \mathrm{influjo} \mathrm{del} \mathrm{Art} \mathrm{Nouveau}$ se plasma de forma más original, a pesar de las transformaciones y añadidos sufridos

38 POZO FELGUERA, Gabriel: op. cit., s.p. 
tras su construcción. El uso del ladrillo rojo y de azulejo en su paramento, un bellísimo programa ornamental que se extiende por todos los rincones de la fachada y el magnífico trabajo de forja de las barandillas de los balcones y la portada, conforman un amplio repertorio de formas adscritas el Modernismo [9].

Conforme nos acercamos al extremo meridional de la Gran Vía, las manifestaciones modernistas van perdiendo fuerza, aunque siguen siendo patentes en algunos dinteles y detalles decorativos de los miradores. El último de los bloques de esta acera es el conocido como Edificio Colón, que tiene la entrada principal en la calle Reyes Católicos. A través de ella, accedemos a un recibidor donde podemos apreciar una puerta de acceso al interior del inmueble de marcado sabor modernista, así como un esgrafiado decorativo en la parte inferior de los paramentos tendente al Modernismo geométrico [10]. Asimismo, la rejería de los balcones externos del primer y tercer piso posee latiguillos de tradición Art Nouveau.

Pasando a la acera de los números pares, el conjunto más destacado en cuanto a Modernismo es el de la "Casa del Americano", compuesta por tres inmuebles de renta que forman una sola manzana de fachada homogénea. El diseño de los frentes arquitectónicos parte de nuevo de una base academicista, aunque salpicada de abundantes detalles modernistas que le aportan novedad y dinamismo, y que se localizan en los esgrafiados que decoran los huecos de los tres últimos pisos y la entrada principal, los relieves de ménsulas y pinjantes y en el remate de la edificación. Además, el tono rojizo del paramento, que imita sillería, contribuye a su originalidad, separándola en apariencia de los demás bloques de la calle.

Del resto de inmuebles que componen la acera de los pares, poco significativos son los escasos elementos modernistas que vienen a matizar muy levemente el Eclecticismo de sus frontispicios.

Los alrededores de esta gran avenida presentan también algunos casos de influjo arquitectónico modernista. El número 14 de la calle Azacayas, perpendicular a la Gran Vía, posee molduras en los dinteles del cuerpo principal de su fachada con pronunciados elementos florales que recuerdan mucho a esquemas ornamentales vistos anteriormente, como el del número 10 de la calle Rejas de la Virgen en el caso de los vanos del primer piso, o el que se repetía en los inmuebles del Callejón de Arjona, calle Mirasol y Plaza Campo Verde en los del piso superior.

En la calle Elvira, primitivo eje de la medina, apreciamos igualmente un lejano eco modernista en las monteras de la luz del número 108; y las del hotel Puerta de las Granadas, en la cuesta de Gomérez, combinan Modernismo naturalista y geométrico en una composición ciertamente similar a la de las molduras del número 37 de la calle San Antón.

La calle Reyes Católicos, que nace tras el embovedado del río Darro en el siglo XIX, presenta, en unos cuantos alzados, ligerísimas pinceladas decorativas evocadoras, en cierta medida, de un Modernismo muy esquemático. 

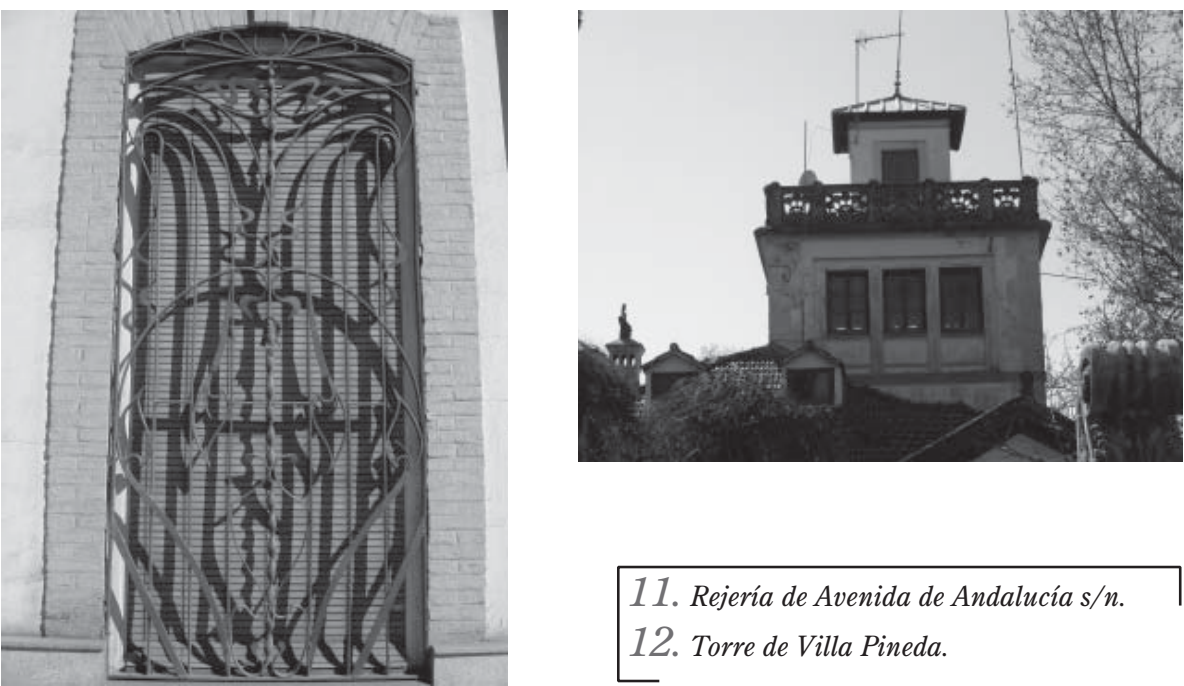

\subsection{Realejo.}

El antiguo arrabal judío de Granada es poco fértil en lo que a decoración modernista de fachadas se refiere, pese a ocupar un amplio sector urbano y combinar en sus calles arquitecturas de muy diversas épocas históricas.

El actual Palacio de los Duques de Gor es una reconstrucción de la casa de los mismos propietarios que existía con anterioridad en el mismo emplazamiento, y que estaba basada en un proyecto de finales del siglo XIX de Francisco Giménez Arévalo ${ }^{39}$. La fachada posee en su mayor parte elementos eclécticos e historicistas, pero la banda de piedra que recorre la cornisa está tallada con mascarones y pequeñas flores que evocan el Modernismo.

En la plaza más importante del barrio, la del Campo del Príncipe, se ubica el bar "La Esquinita", en un pequeño inmueble de tipología popular. Los rígidos dinteles de sus huecos se adornan con motivos geométricos que de nuevo nos llevan a pensar en el sezessionismo. Un tipo de decoración parecida será la que ornamente el recercado de los vanos del bloque número 8 de la Cuesta del Pescado, del que también es destacable el forjado de sus balcones, con motivos curvos que entroncan con el naturalismo del Art Nouveau. 


\subsection{Periferia.}

En el área que rodea el centro histórico encontramos algunas construcciones dispersas salpicadas de Modernismo. El ejemplo más significativo lo conforman las rejas y barandillas metálicas de una casa de la Avenida de Andalucía sin número, con diseño del más puro estilo Art Nouveau, en el que las barras se retuercen en latiguillos y se ensanchan y estrechan aportando movimiento al conjunto [11].

No muy lejos de allí, en la Antigua Carretera de Málaga, se sitúa la Villa Pineda, rodeada de un precioso jardín de inspiración romántica. Es un edificio de principios del siglo XX de un lenguaje formal básicamente ecléctico, pero con pinceladas modernistas que se concentran en los antepechos labrados del balcón de la torre y en los rigidizadores de obra de la verja de entrada, que son también de piedra [12]. La decoración de los pretiles consta de ramilletes abiertos de flores bastante esquemáticos, y los balaustres que los jalonan se adornan con cabezas de flor con pinjantes; en los rigidizadores se repite el esquema compositivo de círculo y bandas paralelas que ya hemos visto anteriormente en numerosos bloques del centro histórico.

Desplazándonos ahora al extremo opuesto de la ciudad, el meridional, encontramos en la Avenida de Cervantes un par de casos atractivos. El primero de ellos es la iglesia Nuestra Señora de Montserrat, que presenta leves detalles florales tanto en la fachada como en el exterior del crucero. En sus vidrieras, localizadas en el rosetón de la portada y en los brazos del transepto, vuelven a aparecer las flores, esta vez con un carácter más rígido. Un poco más abajo, en la acera opuesta de la avenida, se ubica una sencilla casa de dos plantas, cuyos huecos del piso superior -algunos de los cuales se han cegado- han sido adornados en sus dinteles con originales molduras compuestas por sinuosas líneas que enmarcan motivos florales. A pesar de su simetría, el dinamismo del diseño y la voluptuosidad del esquema ornamental apuntan sin duda hacia el Art Nouveau.

\subsection{Arquitectura funeraria}

Sería injusto no considerar la arquitectura funeraria como parte integrante del patrimonio artístico de la ciudad, por lo que añadimos a lo ya expuesto el legado que el Modernismo ha dejado a los granadinos en el cementerio de San José.

Si, como hemos apuntado a lo largo de estas líneas, el estudio de la herencia modernista en la "ciudad de los vivos" se encuentra en una fase todavía inicial, el de la "ciudad de los muertos", relegada irremediablemente a un segundo plano, es prácticamente inexistente. Se da, sin embargo, una circunstancia excepcional que favorece el análisis artístico de las necrópolis: el carácter sagrado de las sepulturas ha impedido que los derribos y superposiciones sean una actividad frecuente, al contrario de lo que sucede en el mundo urbano.

El Modernismo será un movimiento que encaje bien dentro de los 


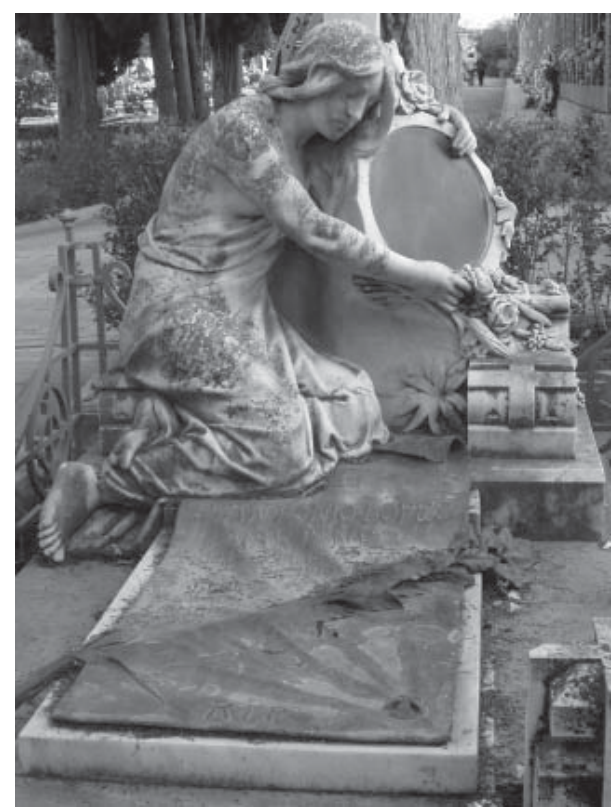

13. Monumento funerario a Don Antonio López Martínez. cementerios por su carácter trascendente y simbólico, y se difundirá por los camposantos de toda Europa en el arranque del siglo XX. En España, Cataluña ocupa también el primer puesto en cuanto a arquitectura funeraria modernista, aunque en la mayoría de los cementerios nacionales se recojan ecos de la misma.

El primer caso reseñable lo encontramos en el pequeño obelisco de perfil bulboso que, a modo de recordatorio fúnebre, se levantó al poeta José Aguilera López en 1903. Tiene decoración labrada en sus cuatro frentes, siendo el principal el que alberga el escudo de Granada y el relieve del busto del escritor. En los laterales, un gran girasol con una corona de laurel -en alusión a lo metafísicopreside los paños, mientras que la parte trasera acoge la inscripción

funeraria, flanqueada por hojas de laurel y rematada por un Crismón.

Otro monumento destacado es el de Don Antonio López Martínez, fallecido en 1913. Consta de un gran crucifijo bajo el que se dispone una elegante y sensual mujer de largos cabellos -el Modernismo recurre constantemente en su iconografía a la figura femenina- abrazada dramáticamente a un marco circular -que posiblemente estuviera destinado en un principio a albergar el retrato del difunto, pero que ha quedado inacabado-, mientras agarra con la mano derecha un ramillete de flores. En la lámina de metal que sirve de soporte para la inscripción dedicatoria, de caracteres inequívocamente modernistas, se inserta otro ramillete, igualmente metálico y maravillosamente trabajado, compuesto por hojas de laurel y espigas de trigo [13].

El tercer y último caso de arquitectura funeraria influenciada por el Art Nouveau en el cementerio de Granada es el de la sepultura levantada posiblemente a Claudio López Castruchi -no se especifica nombre, y las letras grabadas en la piedra apenas son distinguibles a causa de su deterioro-, cuñado del farmacéutico granadino Enrique Hernández Hernández. Se trata nuevamente de un conjunto escultórico pétreo, con una talla de menor calidad que en el caso anterior, a lo que hay que sumar un lamentable estado de conservación. Centra la composición el altorrelieve de un ángel de gran tamaño que llora postrado en escorzo ante la corona floral que enmarca el 
nombre del fallecido. De su busto, situado en la parte superior, bajo la cruz oblicua que remata el conjunto, sólo ha quedado la silueta marcada en la superficie, que nos indica que una vez estuvo allí, aunque haya desaparecido. El Modernismo se hace especialmente patente en la suavidad de las formas casi difuminadas del ángel y sus velados ropajes, así como en el aura que rodea la figura, a medio camino entre el realismo y el simbolismo.

\section{Conclusiones.}

Como ya hemos tenido ocasión de comprobar, la mera afirmación de la existencia de una cierta arquitectura de carácter modernista en la ciudad de Granada es motivo de controversia. Posturas entusiastas que ensalzan las fachadas de la Gran Vía de Colón como prototípicas del nuevo arte, contrastan con las que reducen la presencia de este movimiento a detalles sin importancia en unos pocos inmuebles de la ciudad, o con las que llegan a negar la presencia del Art Nouveau en la arquitectura granadina.

Quizás la postura más sensata sea la de evitar estos extremos. No se trata de ver donde no hay, pero tampoco de negar lo evidente. Es cierto que dentro de España -por supuesto dejando a un lado Cataluña- otras muchas ciudades poseen un patrimonio modernista más rico y variado que el granadino: Melilla, Valencia, Comillas, Zaragoza... Incluso dentro de la propia Andalucía, capitales como Sevilla superan en importancia a Granada. Pero también es indiscutible que, aparte de los situados en la Gran Vía, hay un conjunto de edificios con claras influencias modernistas que están a la espera de ser catalogados y analizados como es debido.

Si tenemos en cuenta que una de las características definitorias del Modernismo es su esencia heterogénea, el individualismo que profesa en cada una de las regiones donde se manifiesta, supone un error evaluar el caso granadino en base a su grado de semejanza con otros tipos de Modernismo mucho más consolidados como el catalán o el belga, pues incluso a nivel andaluz existen marcadas diferencias entre unas zonas y otras. Por otra parte, el hecho de que la pequeña burguesía granadina no fuera comparable en número y capacidad económica a la catalana o la centroeuropea, no supuso un impedimento a la hora de levantar edificios de regusto modernista, a pesar de que en los lugares donde existía una sociedad desarrollada, el Art Nouveau florecía con mucha más facilidad. Posiciones un tanto exageradas como la de Antonio Checa Godoy, que habla de un abierto rechazo por parte de los burgueses de la ciudad hacia el Modernismo ${ }^{40}$, se contradicen con lo que nos muestra la propia geografía urbana: ¿cómo hubiera sido posible, en ese caso, la construcción de tantos bloques salpicados de este estilo en la Gran Vía, que fue precisamente el escaparate de la clase alta en Granada?

Hemos de considerar, además, un aspecto importante que se olvida con relativa frecuencia: el Modernismo desaparecido en la capital. No son pocas las

40 CHECA GODOY, Antonio: op. cit., pág. 358, nota 6. 
construcciones de este tipo que han sido demolidas para dar paso a edificaciones más 'acordes' con las pautas formales y económicas de las últimas décadas del siglo XX. La mayor parte de los casos de derribo han tenido lugar en la Gran Vía, donde, según el profesor Gómez-Moreno, se han destruido «no menos de ocho o diez bloques modernistas» ${ }^{41}$, que han sido sustituidos por una arquitectura que, ciertamente, no se adapta a la estética y las proporciones de la calle. A éstos, que han sido los más sonados, debemos añadir otros ejemplos, como el chalet número 5 de la Bajada de la Escoriaza, desaparecido en la década de los $80^{42}$. Una correcta estimación de la presencia de este arte en las calles granadinas, exige también la revisión de este grupo de inmuebles que sucumbió a las voraces transformaciones urbanas.

Es evidente, no obstante, que no podemos esperar encontrar modelos paradigmáticos del Modernismo en las calles granadinas. Éste se manifiesta, en la mayoría de los casos, en elementos localizados de las fachadas, en las que también pueden apreciarse influencias de otros estilos que imperaron durante las primeras décadas del siglo XX. Consideramos, sin embargo, que el influjo modernista se refleja asimismo en la mayor naturalidad que adquieren determinados ornatos -especialmente los de carácter vegetal- pertenecientes a las corrientes ecléctica o historicista, así como en la proliferación de la decoración floral en numerosos frentes de edificios erigidos durante estos años, y que hemos analizado a lo largo del trabajo ${ }^{43}$.

41 GÓMEZ-MORENO CALERA, José Manuel: "Reflexiones sobre el deterioro monumental de Granada", Cuadernos de Arte de la Universidad de Granada, nº 20, 1989, pág. 142.

42 El estudioso Alberto Villar Movellán es el único que cita dicho inmueble en su alusión al Modernismo granadino (vid. VILLAR MOVELLÁN, Alberto: “El modernismo...”, pág. 177), aunque, cuando lo hace, el edificio aún está en pie (añade incluso la foto de uno de sus vanos).

43 Aunque mucho más escaso que el organicista, el Modernismo geométrico también se manifiesta tímidamente, como hemos constatado, en ciertos detalles decorativos de las fachadas granadinas. 